\title{
Retroaortic and circumaortic left renal veins with their CT findings and review of the literature
}

\author{
İlkan Tatar ${ }^{1}$, Hüseyin Gürkan Töre ${ }^{2}$, H. Hamdi Çelik ${ }^{1}$, Musturay Karcaaltıncaba ${ }^{3}$ \\ ${ }^{1}$ Department of Anatomy, School of Medicine, Hacettepe University Ankara, Turkey \\ ${ }^{2}$ Department of Radiology, School of Medicine, Baskent University, Ankara, Turkey \\ ${ }^{3}$ Department of Radiology, School of Medicine, Hacettepe University Ankara, Turkey
}

\begin{abstract}
Both circumaortic and retroaortic left renal veins are the result of persistence of the dorsal limb of the embryonic left renal vein and of the dorsal arch of the renal collar. However, in retroaortic left renal vein the ventral arch regresses so that a single renal vein passes posterior to the aorta. The approximate prevalence of circumaortic left renal vein is 0.3 to $3.7 \%$, and retroaortic left renal vein is 0.5 to $6.8 \%$. Cross-sectional computerized tomography study was done in both cases. In one of the cases the left renal vein was observed posterior to the abdominal aorta and in the other case the left renal vein was covering the abdominal aorta, one vein superior and posterior and the second vein inferior and anterior to the abdominal aorta. Venous anomalies of the renal veins are clinically important especially in retroperitoneal surgery and intracaval interventions. These anomalies should not be misdiagnosed as dilated gonadal vein, retroperitoneal lymphadenopathies or masses.
\end{abstract}

Key words: renal vein; variation; retroaortic; circumaortic; CT

Anatomy 2008; 2: 72-76, (C) 2008 TSACA

\section{Introduction}

Venous anomalies, mainly resulting from the errors of the embryological development, are frequently observed. Venous anomalies of the retroperitoneal region have clinical implications mainly in retroperitoneal surgeries, in staging of testicular tumors, and in placement of caval filters. They have also particular importance in situations where extensive dissection of the venous system is involved (ie, lymphadenectomy), venous systems are needed for reconstruction (ie, transplantation), or invasion of the venous system by cancer is possible (ie, renal cell cancer with vascular extension). ${ }^{1}$

The development of the renal veins is a part of the complex developmental process of inferior vena cava.
The process starts from the forth week of conception and ends at about the eighth week. There is a vast network of three pairs of parallel veins in communication. These are in the order of appearance; the posterior cardinal veins, the subcardinal veins and the supracardinal veins. ${ }^{2}$

By regression and persistence of these veins, the four segments of the inferior vena cava is formed: Hepatic part: from hepatic vein and hepatic sinuzoids, Prerenal part: from right subcardinal vein, Renal part: from anastomosis between subcardinal and supracardinal veins and Postrenal part: from right subcardinal vein. The renal veins are formed from the persistence of the anastomosis of the subcardinal and supracardinal veins.

Major venous anomalies of inferior vena cava includes: duplication of the inferior vena cava, transposi- 
tion of inferior vena cava (left IVC), circumaortic (left) renal vein, retroaortic (left) renal vein, abscence of the hepatic portion of the inferior vena cava., ${ }^{2,3}$

Both circumaortic and retroaortic left renal veins are the result of persistence of the dorsal limb of the embryonic left renal vein and of the dorsal arch of the renal collar (intersupracardinal anastomosis). However, in retroaortic left renal vein the ventral arch regresses so that a single renal vein passes posterior to the aorta. Circumaortic left renal vein is seen in $0.3 \%$ to $3.7 \%$ and the retroaortic left renal vein is seen in $0.5 \%$ to $6.8 \%$ of the population. ${ }^{4}$

\section{Case Reports}

\section{Case Report 1 - Circumaortic left renal vein Wor}

In a 55 year-old white male, there is a single inferior vena cava ascending superiorly, lateral to the abdominal aorta. The left renal veins form a collar around the abdominal aorta. The superior left renal vein passes anterior to the abdominal aorta just inferior to the celiac artery and, the inferior left renal vein passes posteriorly (Figures 1-3).

\section{Case Report 2 - Retroaortic renal vein}

In a 49 year-old white male, the renal vein is passing posterior to the abdominal aorta draining into the inferior vena cava, which is ascending superiorly in its normal anatomic position right to the abdominal aorta. This patient had visceral organ perforation and the contrast material leaked into the peritoneal cavity, which disturbed the quality of the images (Figures 3-5).

\section{Discussion}

The inferior vena cava is formed from three parallel veins that are subsequently appear and regress; the posterior cardinal veins, the subcardinal veins and the supracardinal veins. The posterior cardinal veins are to develop first, being the vessels of the mesonephrons and largely disappear with these transitory kidneys. The subcardinal veins appear by the fifth week. The subcardinal veins lie in a plane ventral to the aorta, and the supracardinal veins lie in a plane dorsal to the aorta and are interconnected by a network of veins, forming a venous collar around the aorta. The renal veins develop from the anastomosis of the subcardinal and supracardinal veins.

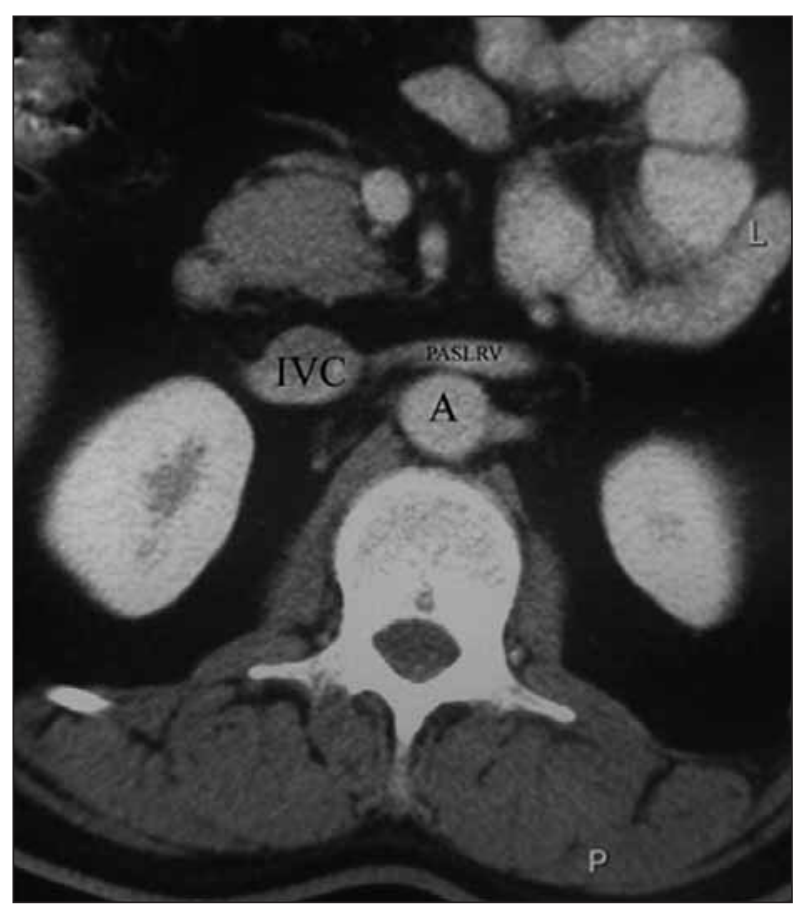

Figure 1. Opening of the circumaortic (PASLRV) vein of case 1 into the IVC. A: abdominal aorta; IVC: inferior vena cava; PASLRV: pre-aortic superior left renal vein. 
Figure 2. Opening of the retroaortic (RAILRV) vein of case 1 into the IVC. A: abdominal aorta; IVC: inferior vena cava; arrow: retro-aortic inferior left renal vein (RAILRV).

Figure 3. The course of the retroaortic (RAILRV) vein of case 1 from left kidney. A: abdominal aorta; IVC: inferior vena cava; arrow: retro-aortic inferior left renal vein (RAILRV).

The subcardinal veins form the stem of the left renal vein, the suprarenal (adrenal) veins, the gonadal veins and the prerenal segment of the inferior vena cava. Lastly, the supracardinal veins develop. They are united
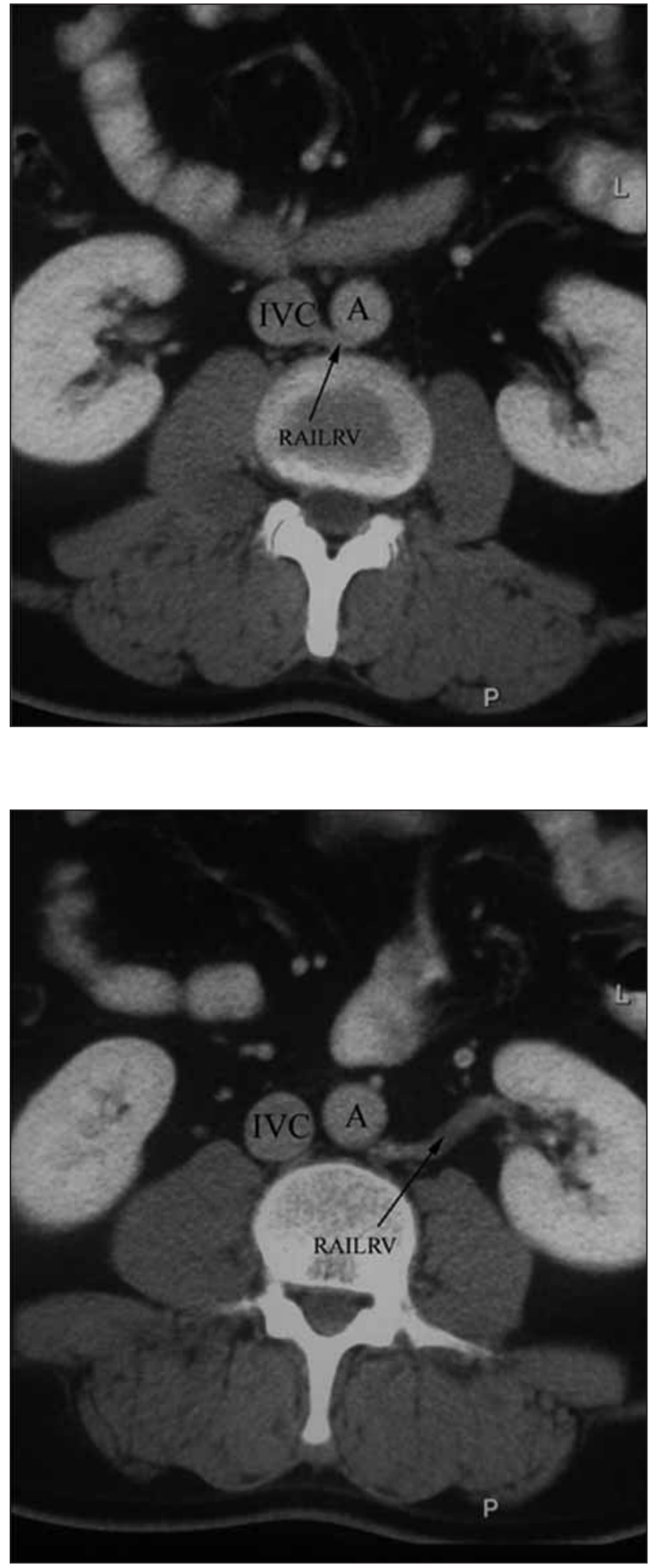

by an anastomosis that is represented in the adult by the azygos and the hemiazygos veins. ${ }^{3,4}$

The renal veins are formed by the anastomoses of the supracardinal and subcardinal veins. Two renal veins 


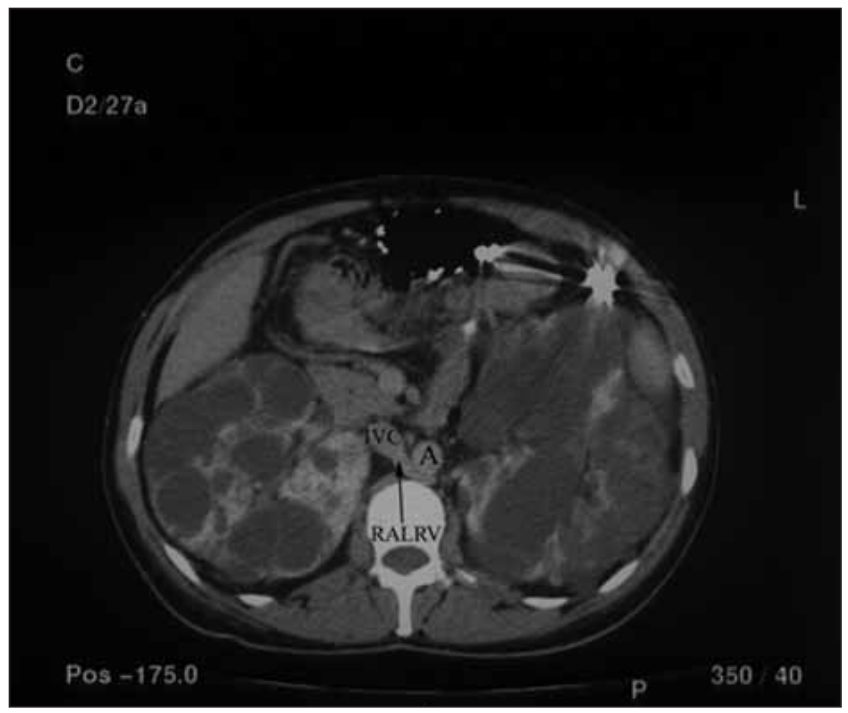

Figure 4. Opening of the retroaortic (RALRV) vein of case 2 into the IVC. A: abdominal aorta; IVC: inferior vena cava; arrow: retro-aortic left renal vein (RALRV).

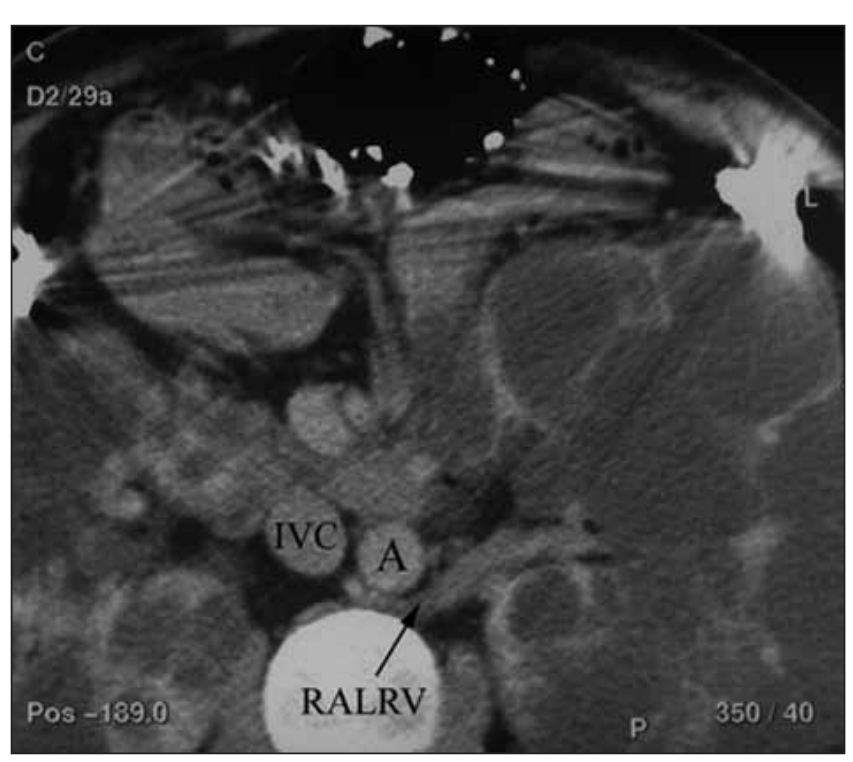

Figure 5. The course of the retroaortic (RALRV) vein of case 2 from polycystic left kidney. A: abdominal aorta; IVC: inferior vena cava; arrow: retro-aortic left renal vein (RALRV).

form as ventral and dorsal; the dorsal vein usually degenerates, the ventral vein forms the renal vein. ${ }^{1,5}$

Circumaortic renal vein is caused by the persistence of the intersupracardinal anastomosis, left subsupracardinal anastomosis, and the left dorsal renal vein. Two renal veins are present; the superior vein passes in front of the aorta at the usual level, the inferior vein runs downward and medially behind the aorta draining into the inferior vena cava at the L3-4 level. ${ }^{1,5,6}$

Retroaortic renal vein is noted to be of two types: Type I develops from the persistence of the left supracardinal anastomosis, the intersupracardinal anastomosis, and the dorsal left left renal vein, with degeneration of the ventral renal vein. Type II is formed by the persistence of the left subsupracardinal anastomosis and the left supracardinal vein. ${ }^{1}$

Reed et al investigated 433 cases in a CT study and found that retroaortic left renal vein and circumaortic left renal vein anomaly was seen in $1.8 \%$ and $4.4 \%$ respectively. ${ }^{7}$ In another CT study of Trigaux et al, they observed 1014 cases and found that retroaortic left renal vein and circumaortic left renal vein anomaly was seen in $3.7 \%$ and $6.8 \%$ respectively. ${ }^{8}$ Among a series of 1008 kidneys studied by Satyapal et al, retroaortic left renal vein and circumaortic left renal vein anomaly was seen in only $0.5 \%$ and $0.3 \%$ respectively.

Diagnosis of the renal vein anomalies is important information in retroperitoneal surgery. Because the unawareness of this situation in retroperitoneal surgery can result in bleeding, nephrectomy and even death. ${ }^{9,10}$

The risk of venous injury is higher in patients with a circumaortic renal collar than in those with an IVC anomaly. The large anterior component of a renal collar can easily mislead the surgeon to think during operation that the development of a left renal vein is normal and that there is no retroaortic component. The posterior component usually runs obliquely, dorsal to the aorta, entering the IVC caudal to the entry of the anterior component. ${ }^{11}$ When proximal aortic isolation is performed blindly, injury to the posterior component of the circumaortic renal collar likely occurs. Circumferential aortic isolation is not recommended when this anomaly is suspected. ${ }^{12}$

Left renal vein prefers due to its length in renal transplantation. Because of this, it is important to know the course of the left renal vein whether pre-aortic or not. It is also important to know anomalies of renal vein for dis- 
tinctive diagnosis of retroperitoneal lymph node pathologies in patients with renal or testicular tumors. ${ }^{13}$

As a conlusion, detailed knowledge about congenital anomalies of the left renal vein is important to make distinctive diagnosis of retroperitoneal lymph node pathologies, masses and renal vascular pathologies and to impede complications, which occur during retroperitoneal vascular surgical procedures.

\section{References}

1. Mathews R, Smith PA, Fishman EK, Marshall FF. Anomalies of the inferior vena cava and renal veins: embryologic and surgical considerations. Urology 1999; 53: 873-80.

2. Moore KL The Developing Human Clinically Oriented Embryology. Philadelphia: W.B. Saunders Company; 1998. p. 352-5.

3. Babian RJ, Johnson DE. Major venous anomalies complicating retroperitoneal surgery. South Med $\mathcal{F}$ 1979; 72: 1254-8.

4. Yesildag A, Adanir E, Koroglu M, Baykal B, Oyar O, Gulsoy UK. Incidence of left renal vein anomalies in routine abdominal CT scans. Tani Girisim Radyol 2004; 10: 140-3.

5. Meyer DR, Huppe T, Andresen R, Friedrich M. Intra- and infrahepatic agenesis of the inferior vena cava with azygos continuation accompanied by duplication of the postrenal segment. Invest Radiol 1998; 33: 113-6.

6. Friedland GW, deVries PA, Nino-Murcia M, King BF, Leder RA, Stevens S. Congenital anomalies of the inferior vena cava: embryogenesis and MR features. Urol Radiol 1992; 13: 237-8.

7. Reed MD, Friedman AC, Nealey P. Anomalies of the left renal vein: analysis of 433 CT scans. 7 Comput Assist Tomogr 1982; 6: 1124-6.

8. Trigaux JP, Vandroogenbroek S, De Wispelaere JF, Lacrosse M, Jamart J. Congenital anomalies of the inferior vena cava and left renal vein: evaluation with spiral CT. 7 Vasc Interv Radiol 1998; 9: 339-45.

9. Satyapal KS, Kalideen JM, Haffejee AA, Singh B, Robbs JV. Left renal vein variations. Surg Radiol Anat 1999; 21: 77-81.

10. Mitty HA. Circumaortic renal collar. A potentially hazardous anomaly of the left renal vein. Am J Roentgenol Radium Ther Nucl Med 1975; 125: 307-10.

11. Parikh SJ, Peters JC, Kihm RH. The anomalous left renal vein: CT appearance and clinical implications. 7 Comput Tomogr 1981; 5: 529-32.

12. Bartle EJ, Pearce WH, Sun JH, Rutherford RB. Infrarenal venous anomalies and aortic surgery: avoiding vascular injury. 7 Vasc Surg 1987; 6: 590-3.

13. Turner RJ, Young SW, Castellino RA. Dynamic continuous computed tomography: study of retroaortic left renal vein. 7 Comput Assist Tomogr 1980; 4: 109-11.

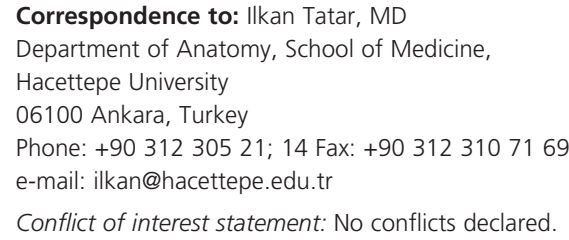

